Article

\title{
Design of a Bicycle Head Lamp Using an Atypical White Light-Emitting Diode with Separate Dies
}

\author{
Hsin-Jung Lin ${ }^{1}$, Ching-Cherng Sun ${ }^{1,2}$, Chi-Shou Wu ${ }^{1}$, Xuan-Hao Lee ${ }^{1, *}$, Tsung-Hsun Yang ${ }^{1}{ }^{1}$, \\ Shih-Kang Lin ${ }^{1}$, Yi-Jou Lin ${ }^{1}$ and Yeh-Wei Yu ${ }^{1}$ \\ 1 Department of Optics and Photonics, National Central University, Chung-Li 320, Taiwan; \\ s107232002@dop.ncu.edu.tw (H.-J.L.); ccsun@dop.ncu.edu.tw (C.-C.S.); \\ s105286005@dop.ncu.edu.tw (C.-S.W.); thyang@dop.ncu.edu.tw (T.-H.Y.); \\ s105286002@dop.ncu.edu.tw (S.-K.L.); s108226030@dop.ncu.edu.tw (Y.-J.L.); ywyu@dop.ncu.edu.tw (Y.-W.Y.) \\ 2 Department of Electrophysics, National Chiao Tung University, Hsin-Chu 30010, Taiwan \\ * Correspondence: s9424006@dop.ncu.edu.tw; Tel.: +886-3-422-7151 (ext. 65277)
}

Received: 13 November 2019; Accepted: 3 December 2019; Published: 9 December 2019

check for updates

\begin{abstract}
To the best of our knowledge, this is the first demonstration of a design for a bicycle head lamp with a high-contrast cutoff line using an atypical white light-emitting diode (LED) with two separate dies. The precise optical model was created by setting the weighting factor on the emitting surface. The downward reflector was designed and fabricated to produce a high-contrast cutoff line in both short- and long-axis orientations, but a yellowish outer pattern was observed. A modified two-color optical model was created to describe the yellowish patterns in both orientations and explain the yellowish effect. Such an effect was caused by the larger coverage area of the phosphor than that by the blue dies. To reduce the yellowish effect near the cutoff line, a specific phosphor area was blocked in the experiment. The yellowish effect was greatly reduced, and the contrast across the cutoff line was enhanced. The presented technology is useful for designing a high-contrast light pattern with such an atypical white LED.
\end{abstract}

Keywords: white LED; k-mark; bicycle head lamp; cutoff line

\section{Introduction}

Vehicle head lamps are crucial for traffic lighting to allow high visibility of the driver, pedestrians, and other people on the road. To prevent glare, a head lamp must have a clear borderline [1,2]. Such a borderline separates the dark and bright zones with minimum contrast, to provide sufficient illumination with less glare. These high-contrast cutoff lines are applicable to cars [3-9], motorcycles [10], and even bicycles [11-14]. In general, most designs apply reflection [3,5,8], projection [6,7,10], and refraction [4,9] to produce a high-contrast cutoff line. By using a combination of various optical principles to design a freeform lens, Chen et al. obtained a highly efficient head lamp to project a high-contrast cutoff line [4]. Wang et al. adopted reflector-lens sets to project a light pattern for a low-beam head lamp [7]. Wu et al. used four reflectors and the parameter-optimization method to obtain a low-beam head lamp with an optical efficiency of 79\% [8]. The contrast requirement for the head lamp cutoff line for bicycles is not as strict as that for automotive vehicles, but the head lamp must be lightweight, compact, and inexpensive. Bicycle head lamps have been studied extensively, and most optical designs use a downward reflector or a total internal reflection (TIR) lens [11-15]. The light source is a solid-state light source (i.e., a light-emitting diode (LED)) because of its advantages, such as compact size, vivid color, fast response, environmental benefits, and long life [16-23]. A so-called phosphor-converted white LED (pcW-LED) produces a white color by using a phosphor to cover a blue die [24]. In a pcW-LED, the phosphor layer or volume is a heavy scattering medium with Mie scattering. As blue light passes 
through the scattering medium, part of the blue light transforms into yellow light to produce white light, while mixing the leakage of blue light [25]. Therefore, the ratio of the yellow and blue light is critical. A pcW-LED used as a light source in a vehicle head lamp should have good heat dissipation, high color accuracy, and high flux density for illumination [26-28]. In general, the pcW-LED operates at $3 \mathrm{~W}$ or more, with as small a light source as possible to contain the phosphor in a conformal coating, meaning that the phosphor area is almost equal to the blue die area [13-15]. This causes higher exitance for sufficient illuminance, and smaller etendue for a high-contrast cutoff line. The light source is therefore relatively expensive. By contrast, if an LED dies outside of expected specifications, it can be used for pcW-LEDs in low-cost lighting applications, such as a light bulb. Such a pcW-LED is not used as a light source in head lamps, and the phosphor area can be larger than that of the blue dies. This paper presents a design for a K-mark bicycle head lamp by using a low-cost and atypical $\mathrm{pcW}$-LED. In the measurement of the fabricated design, a high-contrast cutoff line was observed but with a yellowish blur pattern. An advanced model was used to describe and solve the color problem.

\section{Optical Modeling}

A commercial low-cost pcW-LED with separate dies was used as our light source. The pcW-LED was selected on the basis of its price and other properties, including total flux, exitance, and dimensions. The total flux is a key factor because the illumination distance and visibility of the illuminated target should be clear to a cyclist. Figure 1 illustrates the temporal evolution for the luminous flux, in which the luminous flux reached $150 \mathrm{~lm}$ at steady-state operation under a current injection of $400 \mathrm{~mA}$. This light source is more complicated than others used for bicycles, because two separate dies are bonded under a circular phosphor area. As illustrated in Figure 2, we used a camera to capture the image of the pcW-LED when turned on. To prevent overexposure of the camera, two polarizers were used to adjust the incoming light brightness to an appropriate exposure level for the camera. The images are presented in Figure 3, wherein the axis along the two separate dies is called the long axis, and the other axis is called the short axis. Figure $3 \mathrm{c}$ illustrates the light distribution contour, which was used to define the weighting factor of each emitting point on the top phosphor surface, where the pcW-LED was regarded as a Lambertian light source [29].

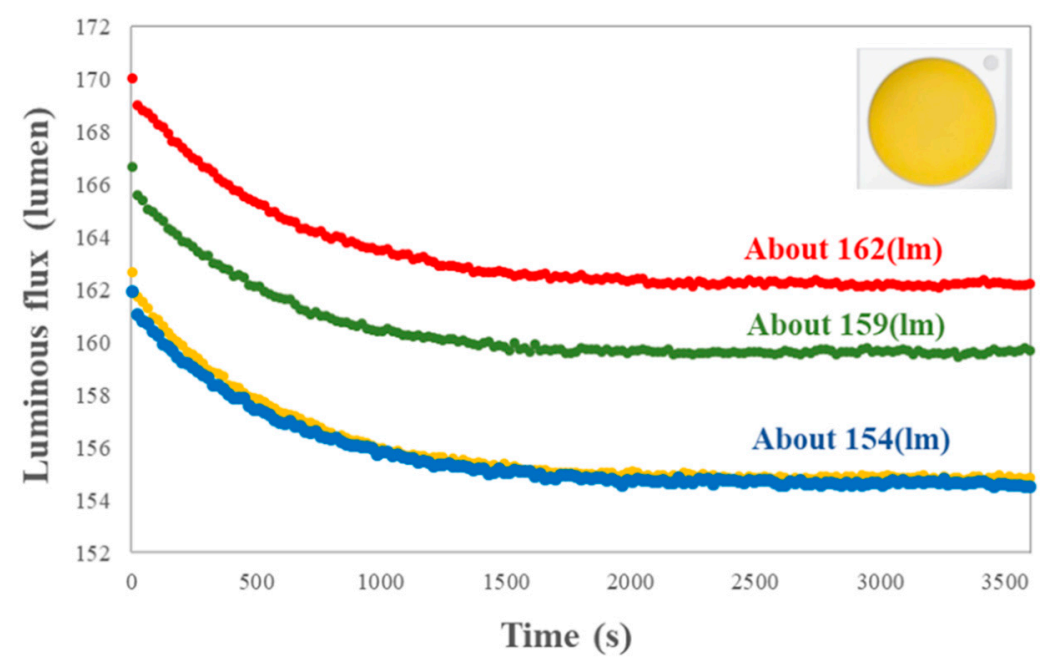

Figure 1. Temporal-dependent luminous flux of the phosphor-converted white LED (pcW-LED).

To verify the validity of the pcW-LED optical model, we compared the simulated light patterns with those measured at different distances in the midfield regime [29-31], where the farthest distance was 10 times the largest lateral size of the emitting area (30 $\mathrm{mm}$ in this case). Figure 4 presents the comparison between the simulated and measured patterns at three distances for two pcW-LED 
orientations. The normalized cross correlation (NCC) values were consistently $>99.5 \%$, which means that the light source model is sufficiently accurate for precise optical design [32].

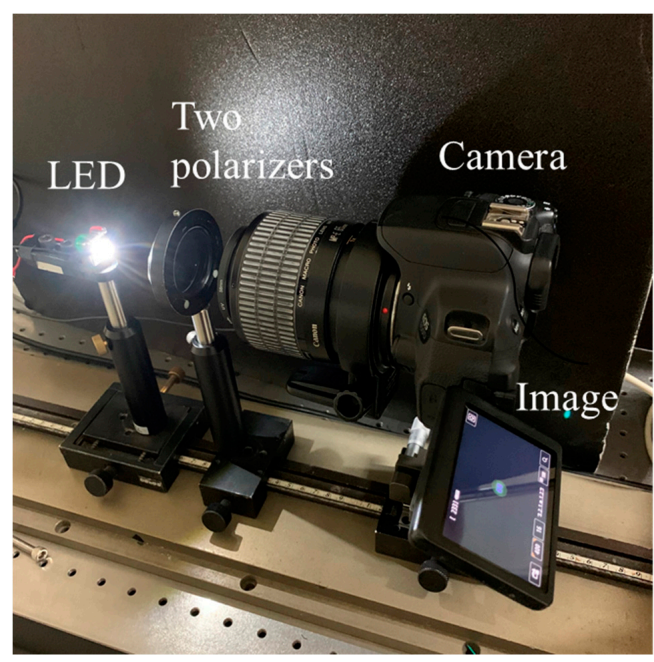

Figure 2. Images of the pcW-LED being captured using a camera.

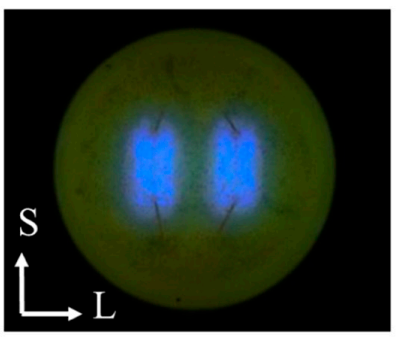

(a)

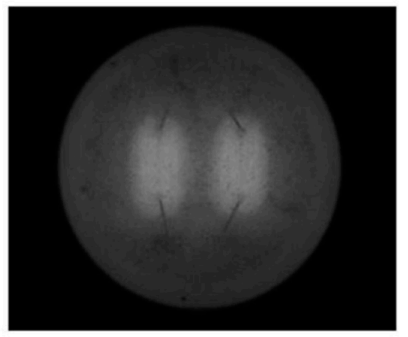

(b)

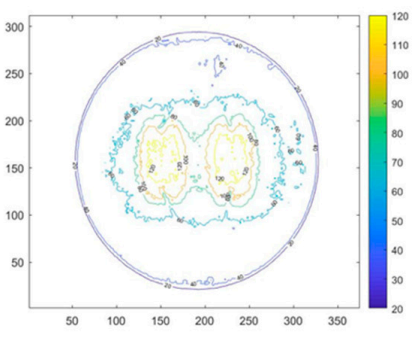

(c)

Figure 3. (a) Color and (b) black-and-white images of the pcW-LED captured using a camera. (c) Gray level distribution of (b). L: long axis, S: short axis.
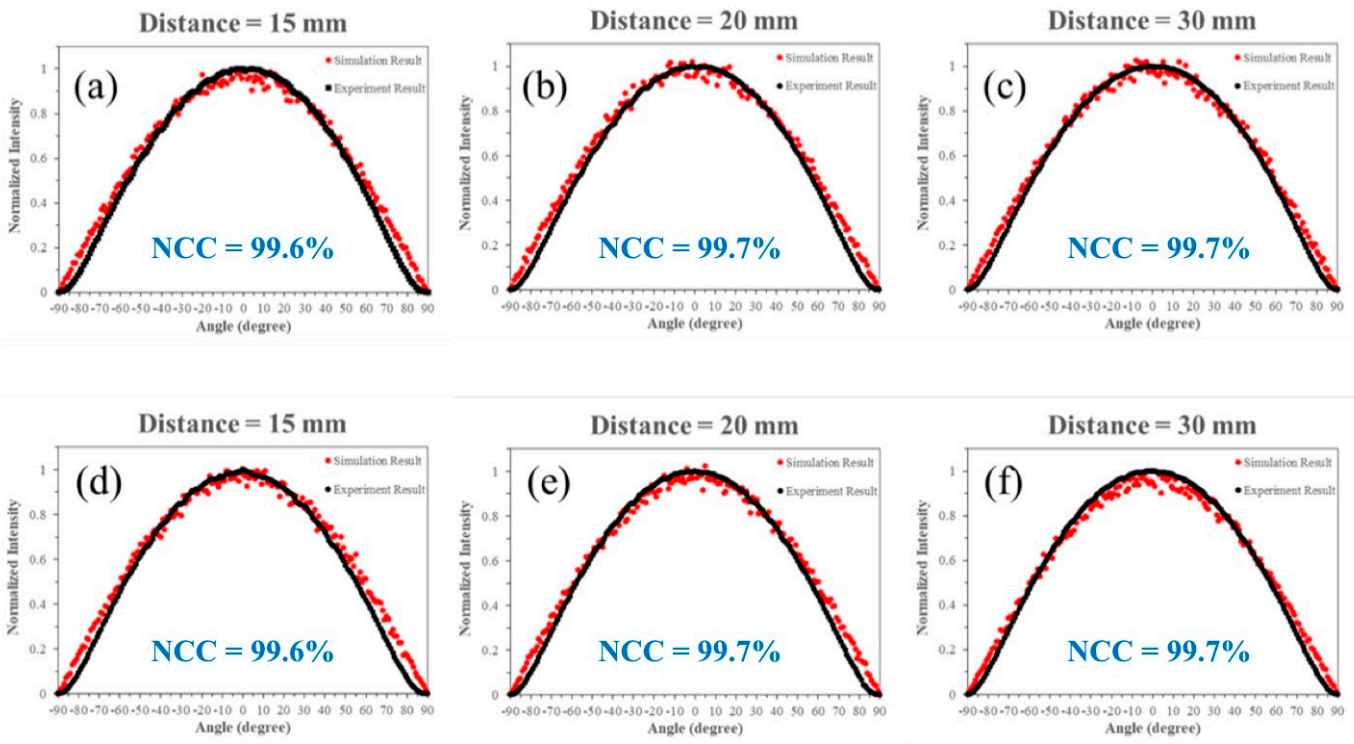

Figure 4. Comparisons between the simulations and measurements at distances of 15, 20, and $30 \mathrm{~mm}$ when the pcW-LED was measured along the $(\mathbf{a}-\mathbf{c})$ short and $(\mathbf{d}-\mathbf{f})$ long axes. 


\section{Optical Design}

The head lamp was designed to pass the K-mark regulation, which is illustrated in Figure 5, wherein several checkpoints were in the illumination plane $10 \mathrm{~m}$ from the head lamp. The first checkpoint is point $A$, where the illuminance should be $\geq 20$ lux and $1 / 1.2$ of the maximum illuminance of the whole field on the plane. Point A should be located at the same horizontal level as the point of the maximum illuminance. The second checkpoint is located in the dark zone above the cutoff line, where the maximum illuminance should be $\leq 2$ lux. In general, the challenge in optical design is ensuring that the illuminance is $\leq 2$ lux in the dark area. In fact, this is related to the vertical location of the maximum illuminance point. If this location is far lower than the cutoff line, the dark zone would be too close to the cutoff line, and too bright to pass the regulation.

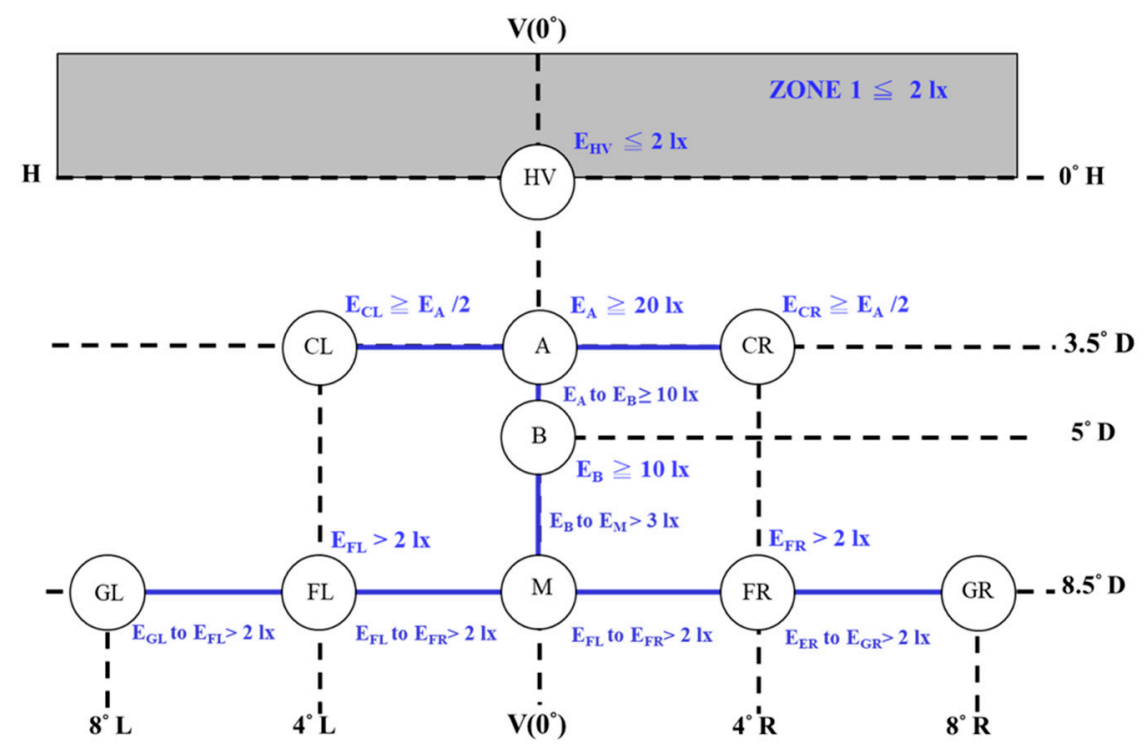

Figure 5. K-mark regulation checkpoints.

An optical design using such a pcW-LED is unusual. The first reason is that the unit has two separate dies. Secondly, the color distribution is not homogenous across the emitting surface. In the design procedure, the optics (i.e., a reflector) were designed on the basis of the white light model. The pcW-LED was attached to the reflector facing downward. The reflector was composed of eight segments, as illustrated in Figure 6, and the four bottom segments were used to form the sharp edge of the cutoff line. To form the cutoff line, the light source area should be as small as possible. However, the dimensions of the pcW-LED along the long axis are not equal to those of the short axis. Typically, the short axis of the pcW-LED should be aligned with the vertical direction because the cutoff line spans across the vertical direction. To increase assembly tolerance, the orientation of the pcW-LED was adjusted to align the long axis of the pcW-LED with the vertical direction. Although this was an undesirable case, after the design was successful, we could change the orientation of the pcW-LED to align the short axis with the vertical axis, to increase the contrast of the cutoff line. Therefore, the orientation of the pcW-LED is not a concern in mass production. Figure 7 illustrates the simulation results, wherein Figure 7a-d display the results of the long- and short-axis orientations, respectively. The simulated illuminance on the checkpoints passed the regulation. However, point $A$, in the case of the long-axis orientation, was farther below the cutoff line than that of the short-axis orientation. This result was as expected, because the illuminance at a dark checkpoint was higher in the long-axis orientation than that in the short-axis orientation. By contrast, the light pattern in the short-axis orientation was wider than that in the long-axis orientation. 


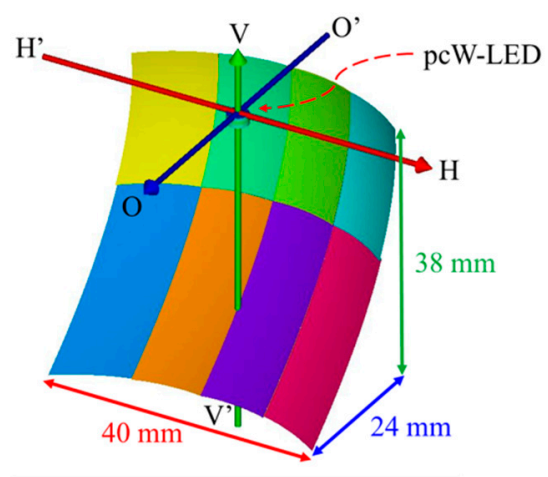

(a)

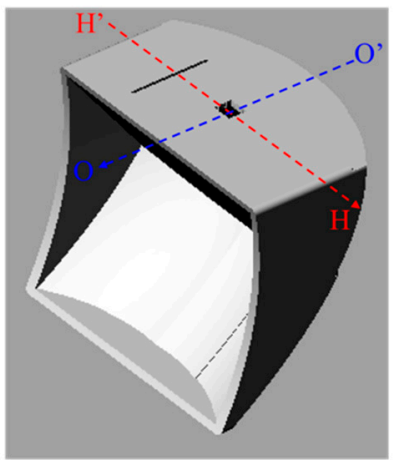

(b)

Figure 6. (a) Geometry of the designed reflector. (b) Reflector with housing.
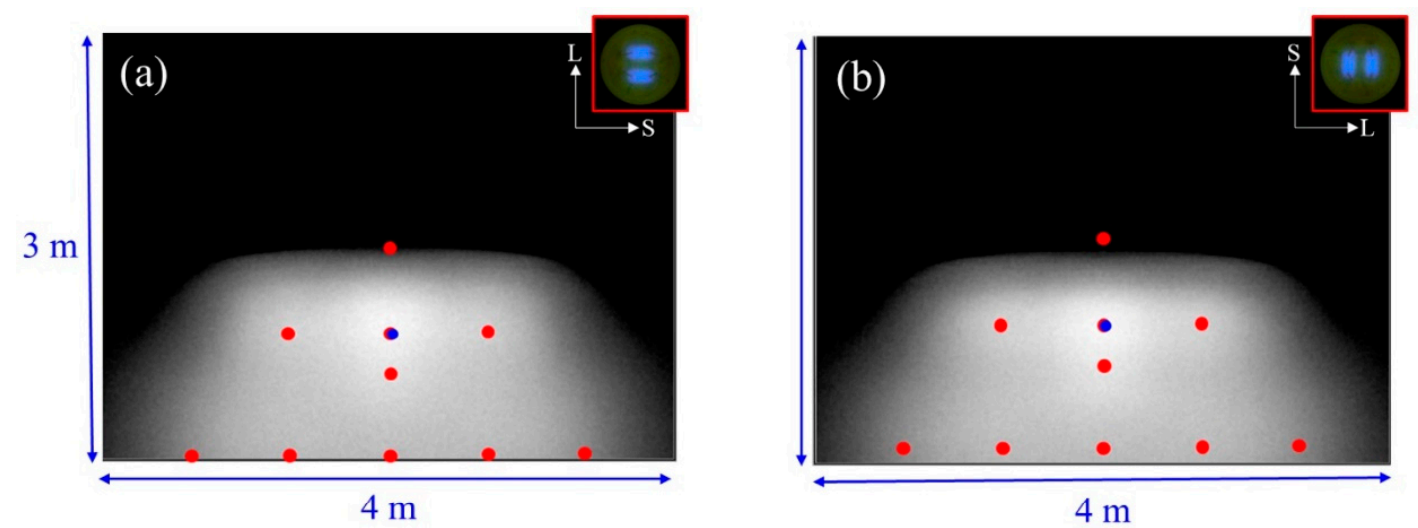

\begin{tabular}{|c|c|c|c|c|}
\hline (c) & K-mark \\
\hline \multicolumn{5}{|c|}{ Contrast : $98(\geqq 10)$} \\
\hline \multicolumn{5}{|c|}{$0.27(\geqq 2)$} \\
\hline & $\begin{array}{c}18.9 \\
(71 \%) \\
\left(\geqq \mathbf{E}_{\boldsymbol{N}} \mathbf{2}\right)\end{array}$ & $\begin{array}{c}26.5 \\
(\geqq 20)\end{array}$ & $\begin{array}{c}18.6 \\
(70 \%) \\
\left(\geqq \mathbf{E}_{\boldsymbol{\Lambda}} / 2\right)\end{array}$ & \\
\hline & & $\begin{array}{c}21.9 \\
(\geqq 10)\end{array}$ & & \\
\hline 7.7 & $\begin{array}{c}14.1 \\
(>\mathbf{2})\end{array}$ & $\begin{array}{c}15.4 \\
(>\mathbf{2})\end{array}$ & $\begin{array}{c}15.2 \\
(>2)\end{array}$ & $\begin{array}{c}7.5 \\
(>\mathbf{2})\end{array}$ \\
\hline$>2$
\end{tabular}

\begin{tabular}{|c|c|c|c|c|}
\hline \multicolumn{2}{|l|}{ (d) } & \multicolumn{3}{|c|}{ K-mark } \\
\hline \multicolumn{5}{|c|}{ Contrast : $\infty(\geqq 10)$} \\
\hline \multicolumn{5}{|c|}{$0(\leqq 2)$} \\
\hline & $\begin{array}{c}18.8 \\
(71 \%) \\
\left(\geqq \mathbf{E}_{\Lambda} / 2\right)\end{array}$ & $\begin{array}{c}26.5 \\
(\geqq 20)\end{array}$ & $\begin{array}{c}18.9 \\
(71 \%) \\
\left(\geqq \mathbf{E}_{\boldsymbol{A}} / \mathbf{2}\right)\end{array}$ & \\
\hline & & $\begin{array}{r}23.9 \\
(\geqq 10)\end{array}$ & & \\
\hline $\begin{array}{l}7.2 \\
(>2)\end{array}$ & $\begin{array}{l}15 \\
(>2)\end{array}$ & $\begin{array}{l}16.1 \\
(>2)\end{array}$ & $\begin{array}{l}14.4 \\
(>2)\end{array}$ & $\begin{array}{l}8.5 \\
(>2)\end{array}$ \\
\hline
\end{tabular}

Figure 7. Light patterns in the case of (a) long- and (b) short-axis alignments with the vertical axis. The blue point represents the maximum illuminance, and the red points represent the checkpoints in the regulation. (c,d) Simulated values at the checkpoints on a plane at a distance of $10 \mathrm{~m}($ (c) and (d) correspond to (a) and (b), respectively). Green numbers are simulated values, and blue numbers are requirements at the checkpoints.

\section{Experimental Verification}

The fabricated reflector is displayed in Figure 8. The reflector was constructed using computer numerical control (CNC) machining and was coated with aluminum film. The reflector was mounted on a table $1 \mathrm{~m}$ above the ground and was located $10 \mathrm{~m}$ away from the illumination plane. The checkpoint measurements for each pcW-LED orientation are presented in Figure 9. The case in which the short axis was aligned with the vertical axis produced a higher-contrast cutoff line and wider horizontal light pattern, compared to the case of the long-axis alignment. Moreover, the illuminance at point A in the short-axis case was larger than that in the long-axis case. 

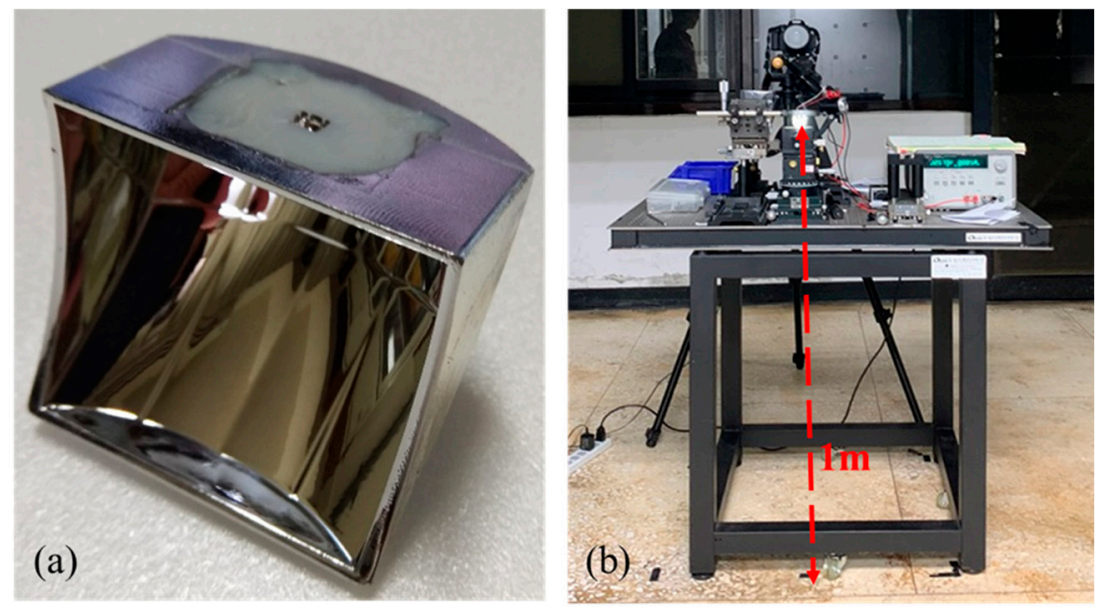

Figure 8. (a) Fabricated reflector. (b) Measurement setup.
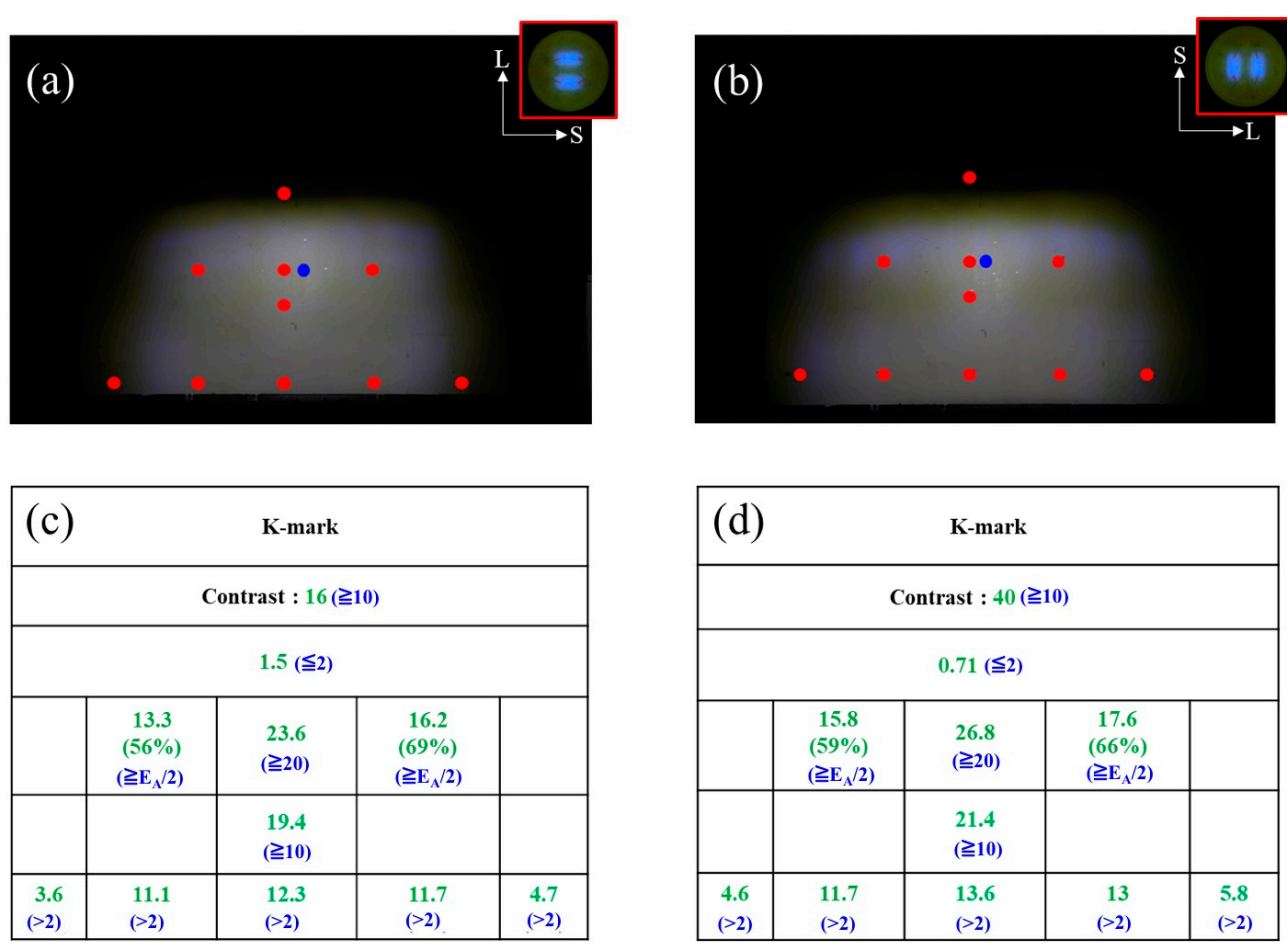

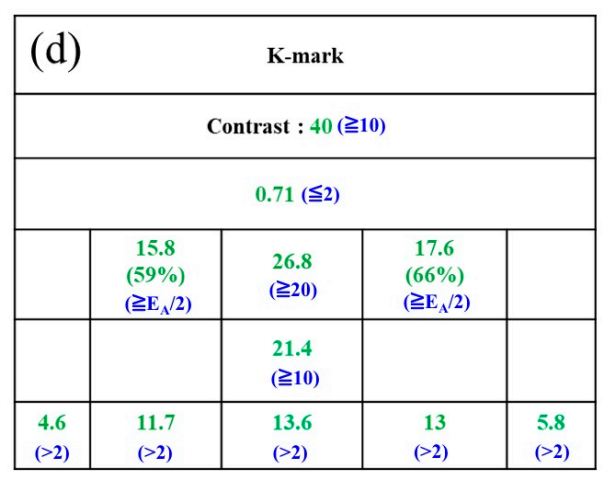

Figure 9. Projected light pattern in the cases of (a) long- and (b) short-axis alignments with the vertical axis. Blue and red points represent maximum illuminance and regulation checkpoints, respectively. (c,d) Measured illuminance at the checkpoints on the plane ((c) and (d) correspond to (a) and (b), respectively).

Although the experimental measurement verified the validity of the optical design, and the light pattern passed K-mark regulation, a new problem occurred. Yellowish light patterns were obvious in both cases of short-axis and long-axis alignment. The short-axis case had a larger yellowish area above the cutoff line, and this was a crucial concern. The yellowish pattern was caused by the light emitting from the LED die area. LED dies can emit light sideward; the down-conversion of yellow light is emitted isotropically, but the blue light is emitted forward. This was the reason that obvious blue light was observed on the top of the LED dies, but yellow light was observed across the whole phosphor area, as illustrated in Figure 10. In the optical design, the reflector was used to reflect incoming light to the target area. In the design, the light source originated from a point source at the center of the pcW-LED. A light source far from the center area causes a blurring of the light pattern, which explains the yellowish light originating from the outer area of the pcW-LED. To describe this phenomenon, 
we attempted to capture the surface light distribution of the pcW-LED in two colors, as illustrated in Figure 10a,c. The distribution was used to modify the pcW-LED optical model. The simulation results are presented in Figure 11, wherein the difference in light patterns produced by blue and yellow lights are obvious. The yellowish light in the outer area is easily observed.
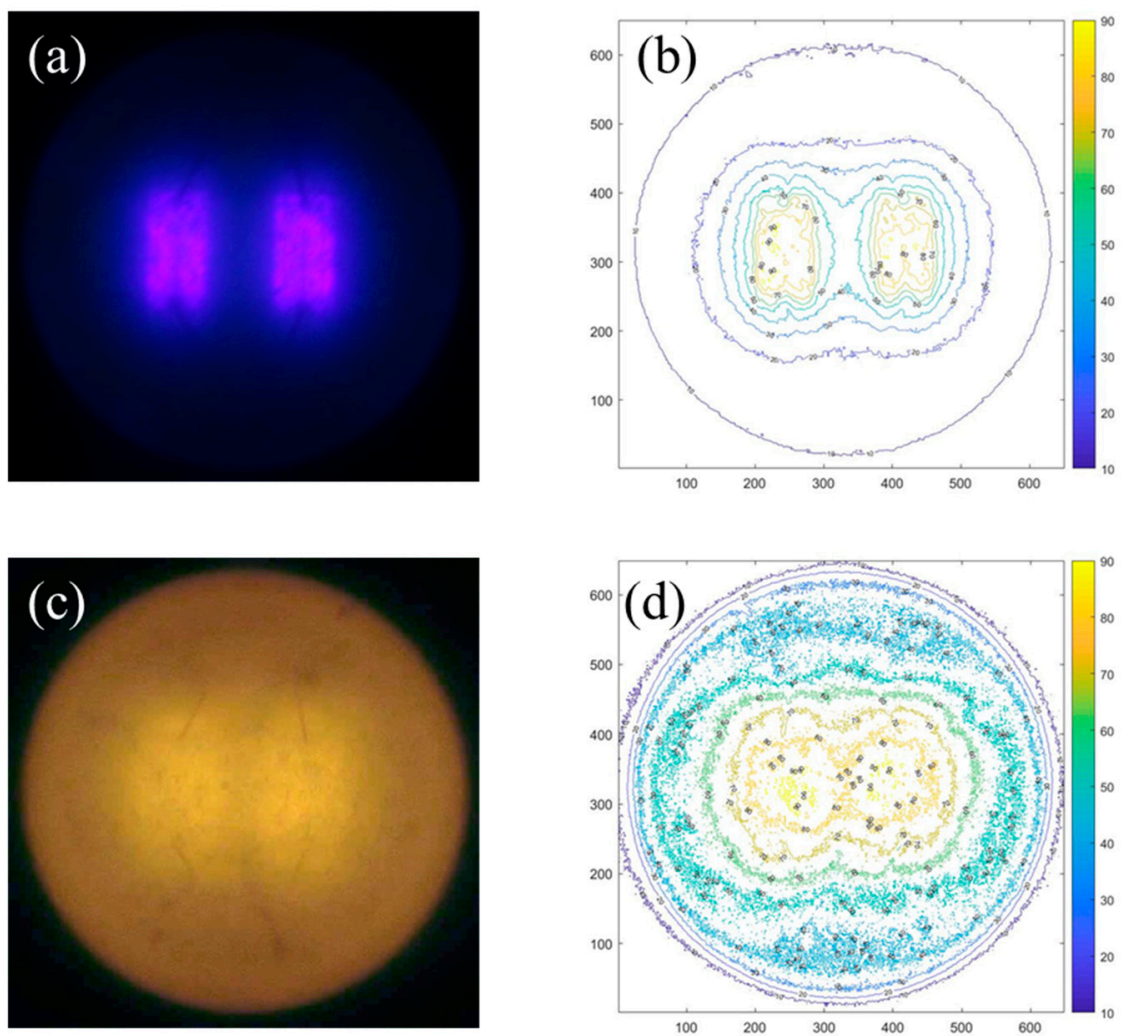

Figure 10. (a) Blue light pattern and (b) the corresponding distribution contour. (c) Yellow light pattern and (d) the corresponding distribution contour.
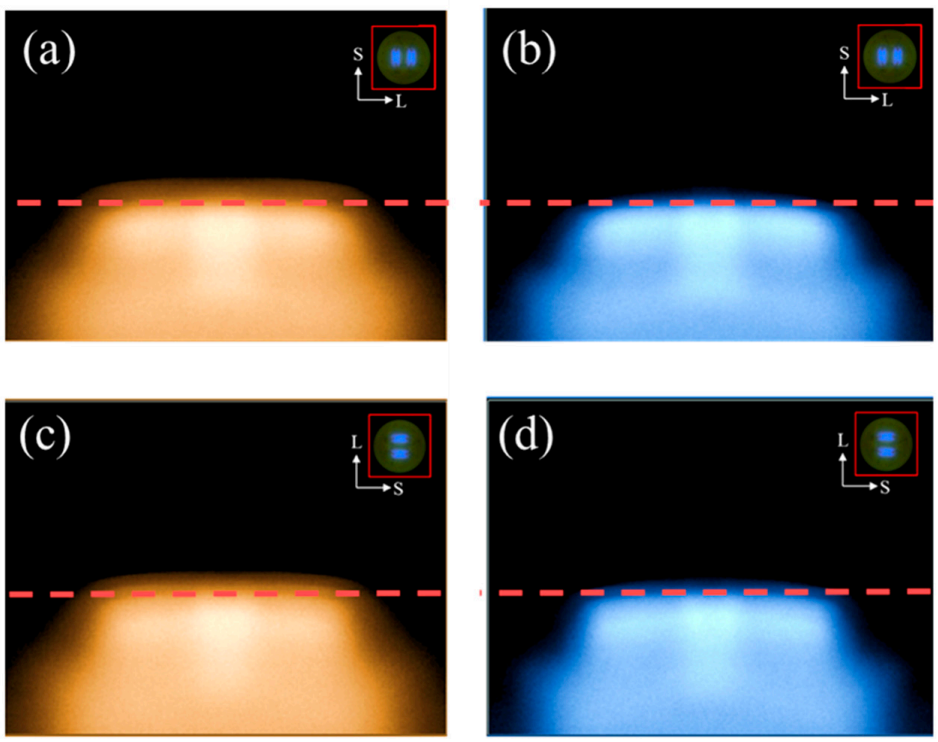

Figure 11. Simulation of the yellow and blue models for the pcW-LED in the cases of $(\mathbf{a}, \mathbf{b})$ short- and (c,d) long-axis alignments. Red dashed lines are used to set the same cutoff lines level for the blue and yellow patterns. Figure colors only distinguish blue or yellow. 


\section{Discussion}

To design a head lamp, light source selection is as crucial as the optical design. In general, the light source should have as small an etendue as possible. Therefore, in a pcW-LED, the LED die should be aligned as tightly as possible. We used an atypical pcW-LED with two separate dies and notably, the phosphor layer covered a larger area than the blue dies did. Thus, the pcW-LED was equipped with a larger etendue, which makes a high-contrast cutoff line difficult to produce. In general, such a pcW-LED is designed for low-cost applications and is not a candidate for a head lamp. By using a design with eight segments, we fabricated a reflector to form the cutoff line. The optical design is typical, but the light source is not. The experimental result demonstrated that the contrast of the cutoff line can pass the regulation by using an appropriate optical design, but the light pattern is yellowish. The yellowish pattern is caused by the large phosphor coverage area. Figure 11 illustrated that the yellow pattern was larger than the blue pattern. Changing this situation is difficult in any optical design, except by using a light guide to color mix blue and yellow light. However, color mixing causes more blur in the illumination light pattern. Because the optical power emitted from the area is not dominant compared with that on top of the blue die, we could block part of the phosphor area to reduce the yellowish pattern near the cutoff line. In the optical design, the center and upper areas of the $\mathrm{pcW}$-LED are the most crucial in forming the cutoff line. Thus, we darkened the upper phosphor area of the light source as illustrated in Figure 12a. In comparison with Figure 9b, the yellowish effect near the cutoff line was greatly reduced. Moreover, the illuminance in the dark zone decreased to 0.4 lux, from 0.71 lux in the original case. As a result, reducing a specific phosphor area is useful for forming a high-contrast cutoff line, as well as reducing the yellowish effect. This technology will be crucial in similar applications when using an atypical pcW-LED. Besides, in the case of using this technology, we examined if the experimental results meet the K-mark regulation. Firstly, the illuminance at point A was measured at larger than 20 lux with a cover. Additionally, the illuminance at points CL and CR were as large as $60 \%$ of the maximum illuminance in the target region. Furthermore, the illuminance at the point $\mathrm{B}$ was around 20 lux, which is two times the 10 lux requested in the K-mark regulation. Finally, the illuminance at the points GL, FL, M, FR, GR are larger than 2 lux. As a result, all checkpoints in the measurement pass the K-mark regulation.



(b)

\begin{tabular}{|c|c|c|c|c|}
\hline & \multicolumn{3}{|c|}{ Contrast : $57(\geqq 10)$} & $\mathrm{E}_{\max }=23.1 \mathrm{~lx}$ \\
\hline \multicolumn{5}{|c|}{$0.4(\leqq 2)$} \\
\hline & $\begin{array}{c}15.4 \\
(68 \%) \\
\left(\geqq \mathrm{E}_{\mathrm{A}} / 2\right)\end{array}$ & $\begin{array}{l}22.7 \\
(\geqq 20)\end{array}$ & $\begin{array}{c}15 \\
(66 \%) \\
\left(\geqq \mathbf{E}_{\mathrm{A}} / 2\right)\end{array}$ & \\
\hline & & $\begin{array}{c}18.6 \\
(80.5 \%) \\
(\geqq 10)\end{array}$ & & \\
\hline $\begin{array}{c}4.2 \\
(>2)\end{array}$ & $\begin{array}{l}10.8 \\
(>2)\end{array}$ & $\begin{array}{l}11.9 \\
(>2)\end{array}$ & $\begin{array}{l}11.1 \\
(>2)\end{array}$ & $\begin{array}{l}3.7 \\
(>2)\end{array}$ \\
\hline
\end{tabular}

Figure 12. (a) Illumination pattern with reduced phosphor area. (b) Measured illuminance at the checkpoints.

\section{Conclusions}

We presented a new design for a K-mark head lamp based on a low-cost pcW-LED, wherein two separate dies were bonded under a wide phosphor layer. Therefore, the head lamp had two feature axes: a long axis along the die-separation line and a short axis. The study started by measuring the steady-state luminous flux to confirm the power level. We then developed a precise optical model for the pcW-LED with a black-and-white image to determine the weighting factor at the emitting surface. The NCCs were all $\geq 99.5 \%$, meaning that the optical model was sufficiently accurate for 
head lamp design. The downward-type reflector was divided into eight segments, of which the four bottom segments were used to form the sharp edge of the cutoff line. After the addition of a housing structure by using CNC machining and aluminum coating, an experimental setup based on K-mark regulation was used to measure the light patterns projected on a plane $10 \mathrm{~m}$ away from the light source. Measurements at the checkpoints revealed that the light patterns with long-and short-axis orientations met the K-mark regulation. A sharper cutoff line was observed when the short axis was aligned with the vertical direction. However, yellowish patterns on the outer area of the projected patterns were observed for both orientations. This phenomenon was caused by a much wider spreading area of the phosphor layer, than the area occupied by the blue die. The side-emitting blue light from the LED die causes more yellow light to emit in the phosphor layer on the outer part. To understand this effect, we created an advanced optical model with blue and yellow light. The new model well described the phenomenon of the yellowish projected light pattern. Finally, we demonstrated an atypical pcW-LED at low cost for application in a K-mark bicycle head lamp, and the extraordinary effects were theoretically analyzed. To reduce the yellowish pattern near the cutoff line, we proposed blocking a specific phosphor area by darkening the upper area of the pcW-LED. The experiment had a positive result, in which the yellowish effect was greatly decreased, and a high-contrast cutoff line was observed. The result well satisfies the requirement in the K-mark regulation. Analyzing the yellowish effect and blocking the phosphor area will be useful and helpful when using a large phosphor coverage area in an atypical pcW-LED to design a head lamp.

Author Contributions: Conceptualization and writing work, C.-C.S.; Simulation, H.-J.L., C.-S.W. and T.-H.Y.; Experiment, H.-J.L. and C.-S.W.; discussion, X.-H.L., S.-K.L., T.-H.Y., Y.-J.L. and Y.-W.Y.

Funding: This research was funded by the Ministry of Science and Technology of the Republic of China, grant numbers MOST 106-2221-E-008-065-MY3 and 108-2622-E-008-010-CC2.

Acknowledgments: The author would like to thank Breault Research Organization (BRO), Inc. for sponsoring ASAP software, and Benex for supporting the fabrication of the optical components.

Conflicts of Interest: The authors declare no conflict of interest.

\section{References}

1. ISO 6742-12015-Estonian Centre for Standardisation. Available online: https://www.evs.ee/products/iso6742-1-2015 (accessed on 4 December 2019).

2. United Nations Economic Commission for Europe Vehicle Regulations. ECE R112. Available online: http: //www.unece.org/fileadmin/DAM/trans/main/wp29/wp29regs/r112r1e.pdf (accessed on 4 December 2019).

3. Cvetkovic, A.; Dross, O.; Chaves, J.; Benítez, P.; Miñano, J.C.; Mohedano, R. Etendue-preserving mixing and projection optics for high-luminance LEDs, applied to automotive headlamps. Opt. Express 2006, 14, 13014-13020. [CrossRef] [PubMed]

4. Chen, F.; Wang, K.; Qin, Z.; Wu, D.; Luo, X.; Liu, S. Design method of high-efficient LED headlamp lens. Opt. Express 2010, 18, 20926-20938. [CrossRef] [PubMed]

5. Ge, A.; Wang, W.; Du, Z.; Qiu, P.; Wang, J.; Cai, J. High-energy-efficiency optical system for an LED-based headlamp architecture. Appl. Opt. 2013, 52, 8318-8323. [CrossRef] [PubMed]

6. Hsieh, C.C.; Li, Y.H.; Hung, C.C. Modular design of the LED vehicle projector headlamp system. Appl. Opt. 2013, 52, 5221-5229. [CrossRef]

7. Wang, H.; Wang, X.; Li, Y.; Ge, P. Design of a newly projected light-emitting diode low-beam headlamp based on microlenses. Appl. Opt. 2015, 54, 1794-1801. [CrossRef]

8. Wu, H.; Zhang, X.M.; Ge, P.; Yu, J.D. A high-efficiency freeform reflector for a light-emitting diode low-beam headlamp. Light. Res. Technol. 2016, 48, 1005-1016. [CrossRef]

9. Chen, H.C.; Zhou, J.H.; Zhou, Y. Stacking illumination of a confocal reflector light emitting diode automobile headlamp with an asymmetric triangular prism. Appl. Opt. 2017, 56, 1087-1093. [CrossRef]

10. Sun, W.S.; Tien, C.L.; Lo, W.C.; Chu, P.Y. Optical design of an LED motorcycle headlamp with compound reflectors and a toric lens. Appl. Opt. 2015, 54, E102-E108. [CrossRef] 
11. Lo, Y.C.; Chen, C.C.; Chou, H.Y.; Yang, K.Y.; Sun, C.C. Design of a bike headlamp based on a power white-light-emitting diode. Opt. Eng. 2011, 50, 080503. [CrossRef]

12. Lo, Y.C.; Cai, J.Y.; Chen, C.W.; Sun, C.C. A compact bike head lamp design based on a white LED operated at one watt. Opt. Laser Technol. 2012, 44, 1172-1175. [CrossRef]

13. Cai, J.Y.; Lo, Y.C.; Feng, S.T.; Sun, C.C. Design of a highly efficient LED-based bicycle head lamp with additional ground illumination. Light. Res. Technol. 2014, 46, 747-753. [CrossRef]

14. Park, H.J.; Lee, D.K.; Lee, J.M.; Park, K.W.; Joo, J.Y.; Kwak, J.S. Design of LED bicycle headlamp with a horizontally wide viewing angle. Curr. Opt. Photonics 2017, 1, 351-357.

15. Tsai, M.S.; Sun, C.C.; Yang, T.H.; Wu, C.S.; Lin, S.K.; Lee, X.H. Robust optical design for high-contrast cut-off line in vehicle forward lighting. OSA Contin. 2019, 2, 1080-1088. [CrossRef]

16. Narendran, N.; Maliyagoda, N.; Bierman, A.; Pysar, R.; Overington, M. Characterizing white LEDs for general illumination applications. Proc. SPIE 2000, 3938, 240-248. [CrossRef]

17. Steigerwald, D.A.; Bhat, J.C.; Collins, D.; Fletcher, R.M.; Holcomb, M.O.; Ludowise, M.J.; Martin, P.S.; Rudaz, S.L. Illumination with solid state lighting technology. IEEE J. Sel. Top. Quantum Electron. 2002, 8, 310-320. [CrossRef]

18. Zukauskas, A.; Shur, M.S.; Caska, R. Introduction to Solid-State Lighting; John Wiley \& Sons: New York, NY, USA, 2002; ISBN 978-0-471-21574-5.

19. Schubert, E.F.; Kim, J.K. Solid-state light sources getting smart. Science 2005, 308, 1274-1278. [CrossRef] [PubMed]

20. Schubert, E.F. Light-Emitting Diods, 2nd ed.; Cambridge University Press: New York, NY, USA, 2006; ISBN 9780521865388.

21. Krames, M.R.; Shchekin, O.B.; Mueller-Mach, R.; Mueller, G.O.; Zhou, L.; Harbers, G.; Craford, M.G. Status and future of high-power light-emitting diodes for solid-state lighting. J. Disp. Tech. 2007, 3, 160-175. [CrossRef]

22. Pimputkar, S.; Speck, J.S.; DenBaars, S.P.; Nakamura, S. Prospects for LED lighting. Nat. Photonics 2009, 3, 180-182. [CrossRef]

23. Karlicek, B.; Sun, C.C.; Zissis, G.; Ma, R. Handbook of Advanced Lighting Technology; Springer: Basel, Switzerland, 2017; ISBN 978-3-319-00175-3.

24. Sun, C.C.; Chang, Y.Y.; Yang, T.H.; Chung, T.Y.; Chen, C.C.; Lee, T.X.; Li, D.R.; Lu, C.Y.; Ting, Z.Y.; Glorieux, B.; et al. Packaging efficiency in phosphor-converted white LEDs and its impact to the limit of luminous efficacy. J. Soild State Light. 2014, 1, 19. [CrossRef]

25. Chen, C.Y.; Yang, T.H.; Hsu, C.H.; Sun, C.C. High-efficiency white LED packaging with reduced phosphor concentration. IEEE Photonics Technol. Lett. 2013, 25, 694-696. [CrossRef]

26. Sun, C.C.; Chen, C.Y.; Chen, C.C.; Chiu, C.Y.; Peng, Y.N.; Wang, Y.H.; Yang, T.H.; Chung, T.Y.; Chung, C.Y. High uniformity in angular correlated-color temperature distribution of white LEDs from 2800K to 6500K. Opt. Express 2012, 20, 6622-6630. [CrossRef] [PubMed]

27. Sun, C.C.; Chang, Y.Y.; Wang, Y.H.; Chen, C.Y.; Lo, Y.C.; Cheng, H.H. Precise spatial-color optical modeling in phosphor-converted white LEDs. J. Disp. Technol. 2015, 11, 261-265. [CrossRef]

28. Yang, T.H.; Wu, S.M.; Sun, C.C.; Glorieux, B.; Chen, C.Y.; Chang, Y.Y.; Lee, X.H.; Yu, Y.W.; Chung, T.Y.; Lai, K.Y. Stabilizing CCT in pcW-LEDs by self-compensation between excitation efficiency and conversion efficiency of phosphors. Opt. Express 2017, 25, 29287-29295. [CrossRef]

29. Chien, W.T.; Sun, C.C.; Moreno, I. Precise optical model of multi-chip white LEDs. Opt. Express 2007, 15, 7572-7577. [CrossRef] [PubMed]

30. Sun, C.C.; Lee, T.X.; Ma, S.H.; Lee, Y.L.; Huang, S.M. Precise optical modeling for LED lighting verified by cross correlation in the midfield region. Opt. Lett. 2006, 31, 2193-2195. [CrossRef] [PubMed]

31. Sun, C.C.; Chien, W.T.; Moreno, I.; Hsieh, C.C.; Lo, Y.C. Analysis of the far-field region of LEDs. Opt. Express 2009, 17, 13918-13927. [CrossRef]

32. Lewis, J.P. In Vision Interface 95. Can. Image Process. Pattern Recognit. Soc. 1995, 95, 120-123.

(C) 2019 by the authors. Licensee MDPI, Basel, Switzerland. This article is an open access article distributed under the terms and conditions of the Creative Commons Attribution (CC BY) license (http://creativecommons.org/licenses/by/4.0/). 